\title{
Sustainable Electrochemical Synthesis of Large Grain- or Catalyst-Sized Iron
}

\author{
Fang-Fang $\mathrm{Li}^{1} \cdot$ Baohui Wang ${ }^{1} \cdot$ Stuart Licht $^{1}$
}

Published online: 2 June 2016

(c) The Author(s) 2016. This article is published with open access at Springerlink.com

\begin{abstract}
Electrolytic production of iron in molten salts by splitting iron oxide into iron metal and $\mathrm{O}_{2}$ is a low-carbon footprint alternative to the massive $\mathrm{CO}_{2}$ emissions associated with conventional carbothermal iron production and permits. This study advances a $\mathrm{CO}_{2}$-free method for iron production, by modifying iron electrosynthesis in molten $\mathrm{Li}_{2} \mathrm{CO}_{3}$ to control iron product particle size and by decreasing the electrolyte extracted with the pure iron product. We present the first study of electrolytic iron micro-morphology as formed from iron, and demonstrate it is strongly influenced by the deposition conditions. Particle size and morphology are critical characteristics in a variety of metal applications. In this study, large $(\sim 500 \mu \mathrm{m})$ iron particles are formed at low current densities during extended electrolysis, or at high $\mathrm{Fe}(\mathrm{III})$ concentrations, and small $(\sim 10 \mu \mathrm{m})$ at high current density and low $\mathrm{Fe}(\mathrm{III})$. Deposited $\mathrm{Fe}$ is fiber shaped from equal molals of $\mathrm{Fe}_{2} \mathrm{O}_{3}$ and $\mathrm{Li}_{2} \mathrm{O}$, but particle-like from electrolytes with surplus $\mathrm{Li}_{2} \mathrm{O}$. Iron is formed at high current efficiency, and the observed electrolysis potential decreases with (i) the decreasing current density, (ii) addition of $\mathrm{Li}_{2} \mathrm{O}$, (iii) the increasing anode area, and (iv) the increasing temperature.
\end{abstract}

Keywords Iron production - Carbon dioxide mitigation . Molten carbonate $\cdot$ Iron electrochemistry

Stuart Licht

slicht@gwu.edu

1 Department of Chemistry, George Washington University, Washington, DC 20052, USA

\section{Introduction}

The prevalent form of iron oxide used for iron production is hematite, $\mathrm{Fe}_{2} \mathrm{O}_{3}$. Iron and steel manufacturing is the largest industrial source of greenhouse gases contributing $7 \%$ of the total world's emissions from human activities [1]. In the iron smelting process, metallic iron is formed via carbon reduction at high temperature in accordance with the reaction:

$\mathrm{Fe}_{2} \mathrm{O}_{3}+3 / 2 \mathrm{C} \rightarrow 2 \mathrm{Fe}+3 / 2 \mathrm{CO}_{2}$

The $\mathrm{Fe}_{2} \mathrm{O}_{3}$ reduction reaction, Eq. 1, is endothermic, requiring the heat of burning additional carbon, and releasing additional carbon dioxide in addition to that generated in Eq. 1, exacerbating the carbon dioxide pollution due to conventional iron production. Iron and oxygen can be formed by electrolysis in molten iron oxide, but that process is constrained by material challenges of the very high melting point of iron oxide $\left(1550{ }^{\circ} \mathrm{C}\right)[2,3]$. Iron oxides (both hematite, as well as another common iron oxide, magnetite, $\mathrm{Fe}_{3} \mathrm{O}_{4}$ ) while insoluble in sodium or potassium carbonates become highly soluble (containing up to $50 \%$ by weight iron oxide) in lithiated molten carbonates [4-7]. The melting point of the $\mathrm{Li}, \mathrm{Na}, \mathrm{K}$ carbonate eutectic is $399{ }^{\circ} \mathrm{C}$ and that of pure $\mathrm{Li}_{2} \mathrm{CO}_{3}$ is $723{ }^{\circ} \mathrm{C}$, and both can dissolve high concentrations of iron oxide. This solubility is observed as the soluble salt $\mathrm{LiFeO}_{2}$ which is formed in combination with $\mathrm{Li}_{2} \mathrm{O}$ [6]:

$\mathrm{Fe}_{2} \mathrm{O}_{3}+\mathrm{Li}_{2} \mathrm{O}($ soluble $) \rightarrow 2 \mathrm{LiFeO}_{2}$ (soluble in molten $\mathrm{Li}_{2} \mathrm{CO}_{3}$ )

The high iron oxide solubility in molten carbonate suggests a non- $\mathrm{CO}_{2}$-emitting electrolytic process for the production of iron in which iron ore $\left(\text { as } \mathrm{Fe}_{2} \mathrm{O}_{3} \text { or } \mathrm{Fe}_{3} \mathrm{O}_{4}\right)^{5}$ dissolves in molten carbonate at $\sim 750{ }^{\circ} \mathrm{C}$ ) and is split by 
electrolysis at low voltage and high current efficiency into iron metal and oxygen without carbon dioxide emission [5].

No carbon dioxide is emitted when the heat for this electrolytic production of iron metal is provided by solar energy converted to thermal energy, and the electrolysis current is provided by solar or other renewable energy converted to electronic energy. The splitting of $\mathrm{Fe}_{2} \mathrm{O}_{3}$ into $\mathrm{Fe}$ (metal) and $\mathrm{O}_{2}$ is endothermic, and the thermodynamic electrolysis potential $\left(1.28 \mathrm{~V}\right.$ at $\left.25^{\circ} \mathrm{C}\right)$ falls with the increasing temperature. The general solar thermal electrochemical process (STEP) of sunlight to decrease (endogenic) electrolysis potentials leads to high solar energy conversion efficiencies [6-11]. A variety of other STEP electrolyses have been demonstrated to decrease $\mathrm{CO}_{2}$ including the production of cement, ammonia, fuels, and carbon for the direct removal of atmospheric or smokestack carbon dioxide [10-20]. Fundamental, electrochemical, and impurity effects on STEP iron have been investigated [8], and the general effects of alkali earth and hydroxide on STEP processes in molten carbonates have been reported [14-20]. The fundamental increase in solar electrolysis efficiency with the use of solar thermal has been analyzed for $\mathrm{CO}_{2}$ and $\mathrm{H}_{2} \mathrm{O}$ splitting theoretically [10-12] and experimentally [13-15] and the fundamental endogenic decrease in electrochemical potential with the increasing temperature demonstrated for a number of STEP processes [10-20]. The requisite solar thermal heating for any given process will depend on the current density, which controls the overpotential and the net difference between the thermoneutral potential and the applied electrolysis potential.

We have previously delineated the solar, optical, and electronic components of STEP iron [5-8]. In this study, we focus on the electrolysis component of STEP iron. Specifically, we present the first study of the micro-morphology of STEP iron products, as well as the in-process removal of the electrolyte from the deposited metal iron product. We demonstrated the high purity of the iron product obtained [7], but did not study the micro-morphology of this iron. Particle size and morphology are critical characteristics in a variety of metal and metal oxide applications including catalysis, epoxy composites, MRI, drug delivery, magnetic separation, and immobilization of biosubstances [21-23]. In catalytic reactions, the size of the catalyst is one of the factors to affect its catalytic efficiency $[24,25]$. For example, as the catalyst for STEP ammonia synthesis in our previous studies, the iron particle size is critical for its performance [26]. Large iron particles did not catalyze the reaction effectively, while small particles on the order of several microns react with nitrogen and water to form ammonia in molten salts at high rate.

Electrolytic production of iron in molten salts by splitting iron oxide into iron metal and $\mathrm{O}_{2}$ is a low-carbon footprint alternative to the massive $\mathrm{CO}_{2}$ emissions associated with conventional carbothermal iron production and as shown here permits new morphological control over the product. Here, we present the first study of electrolytic iron micro-morphology as formed from iron oxide in molten $\mathrm{Li}_{2} \mathrm{CO}_{3}$. We demonstrate that the electrolytic iron micromorphology product is strongly influenced by the deposition conditions, including the iron particle shape and a twoorder of magnitude variation of iron product particle size. This study advances a $\mathrm{CO}_{2}$-free production method for iron modifying the synthesis to control iron product particle size and by decreasing the electrolyte extracted with the pure iron product.

\section{Experimental}

\section{Chemicals and Materials}

Lithium carbonate (Alfa Aesar, $99 \%$ ), lithium oxide (Alfa Aesar, $99.5 \%$ ), lithium hydroxide (Acros Organics, $98 \%$ ), barium carbonate (Alfa Aesar, 99.5\%), and calcium carbonate (Alfa Aesar, $98 \%$ ) are combined to form various molten electrolytes. Ferric oxide $\left(\mathrm{Fe}_{2} \mathrm{O}_{3}\right)$ (Alfa Aesar, $98 \%$ ) was added to the molten electrolytes.

\section{Electrolysis}

Electrolysis are driven galvanostatically at a fixed current as described in the text. The electrolysis is contained in a high purity alumina crucible $(99.6 \%$, AdValue Technology AL-2100) or Ni crucible (VWR AA35906-KY). Electrolysis used coiled Ni wire (Alfa Aesar, $99.5 \%$ ) as the (oxygen generating) anode. A wide variety of iron and steel wires for coiled cathodes are effective, an economic form (used in this study) is Fi-Shock 14 Gauge, Steel Wire model \#BWC-14200. The electrolysis potential is measured as the voltage between the anode and the cathode at constant current. We have previously reported on STEP cathode or oxygen anode potentials in a variety of molten carbonates [5-20] During electrolysis, the iron product accumulates at the cathode, which is subsequently removed and cooled. Details of STEP electrolysis are provided in references [5-8].

\section{Characterization}

The iron product is washed, and analyzed titrametrically and by PHENOM Pro-X Energy Dispersive Spectroscopy on the PHENOM Pro-X Scanning Electron Microscope. Magnification size bars are indicated on the Scanning Electron Microscopy images, SEM. The procedure for determining total metallic iron in the cathode product is 
(1) The cathode product is ground in mortar and pestle, until it can be sifted and dispersed through a 70-mesh $(212 \mu \mathrm{m})$ sieve.

(2) The ground product is washed with deionized water, and then extracted by vacuum filtration and rinsing the precipitate with deionized water until $\mathrm{pH}$ is near 7. The precipitates, residue, and filter paper are collected to react with $\mathrm{CuSO}_{4}$.

(3) To $0.5 \mathrm{~g}$ of the ground product is added $50 \mathrm{ml}$ of $0.5 \mathrm{M} \mathrm{CuSO}_{4}$, to form

$\mathrm{Fe}+\mathrm{CuSO}_{4} \rightarrow \mathrm{FeSO}_{4}+\mathrm{Cu}$

(4) After boiling this slowly stirred solution for $1 \mathrm{~h}$, it is immediately filtered (to prevent the reaction of $\mathrm{O}_{2}$ with $\mathrm{Fe}^{2+}$ ) with a GF/A (Whatman glass microfiber) filter paper into a $250 \mathrm{ml}$ volumetric flask, and the filter paper is washed with double deionized (18 M $\Omega$ ) water also into the flask, and diluted to $250 \mathrm{ml}$. The iron analysis reliability improves with slow, instead of fast, stirring (an underestimate of the $\mathrm{Fe}^{0}$ content of the product occurs with the increasing speed of stirring) due to the introduction of oxygen, which can convert ferrous to ferric prior to the titration.

(5) $25 \mathrm{ml}$ of the $250 \mathrm{ml}$ filtrate is sampled by pipette into a 250-ml Erlenmeyer flask, and the following solutions are added to the flask: $20 \mathrm{ml}$ of "A", $20 \mathrm{ml}$ of "B", $50 \mathrm{ml}$ of water, and 3 drops of indicator solution "C", where $\mathrm{A}$ : a mix of $50 \mathrm{ml}$ of water with $10 \mathrm{ml}$ concentrated $\mathrm{H}_{2} \mathrm{SO}_{4}$; $\mathrm{B}: 700 \mathrm{ml}$ of water with $150 \mathrm{ml}$ concentrated $\mathrm{H}_{2} \mathrm{SO}_{4}, 150 \mathrm{ml} \mathrm{H}_{3} \mathrm{PO}_{4}$ (binds colored $\mathrm{Fe}^{3+}$, which is colored, as colorless $\mathrm{Fe}\left(\mathrm{HPO}_{4}\right)_{2}^{-}$, to improve clarity of the endpoint); $\mathrm{C}$ : the indicator solution consisting of $0.2 \%$ aqueous Diphenlyamine 4-sulfonic acid sodium salt; D: the titrant consisting of $0.004167 \mathrm{M}(6 \times$ dilution of $0.025 \mathrm{M}) \mathrm{K}_{2} \mathrm{Cr}_{2} \mathrm{O}_{7}$ which titrates as 1 equivalent $\mathrm{K}_{2} \mathrm{Cr}_{2} \mathrm{O}_{7}$ per $\mathrm{FeSO}_{4}$; for each $\mathrm{ml}$ of solution, $\mathrm{D}=1.3962 \mathrm{mg}$ of $\mathrm{Fe}^{\circ}$ metal.

$$
\begin{aligned}
& 6 \mathrm{FeSO}_{4}+\mathrm{K}_{2} \mathrm{Cr}_{2} \mathrm{O}_{7}+\mathrm{H}_{2} \mathrm{SO}_{4} \\
& \quad \rightarrow 3 \mathrm{Fe}_{2}\left(\mathrm{SO}_{4}\right)_{3}+\mathrm{K}_{2} \mathrm{SO}_{4}+\mathrm{Cr}_{2}\left(\mathrm{SO}_{4}\right)_{3}+7 \mathrm{H}_{2} \mathrm{O}
\end{aligned}
$$

The endpoint is observed as a color change from light blue (initial) to the endpoint's purple.

This titration analysis is also confirmed by weighing the mass of magnetically removed the iron product that was washed \& dried to remove oxide. The need to switch to a lower stirring speed for the $\mathrm{Fe}^{0}$ analysis was discovered and applied to the latter half of the experiments in this study. Under this latter condition replicate analyses of $\mathrm{Fe}^{0}$ metal mass from are reproducible to within $\mathrm{a} \pm 2 \%$.

\section{Results and Discussion}

The melting point of lithium carbonate, $\mathrm{Li}_{2} \mathrm{CO}_{3}$, is $723{ }^{\circ} \mathrm{C}$. This melting point decreases with the increasing concentrations of added salts [7]. The high iron oxide solubility in molten lithium carbonate led us to a non- $\mathrm{CO}_{2}$ emitting electrolytic process for the production of iron:

$2 \mathrm{LiFeO}_{2}($ soluble $) \rightarrow 2 \mathrm{Fe}+\mathrm{Li}_{2} \mathrm{O}($ soluble $)+3 / 2 \mathrm{O}_{2}$

Lithium oxide liberated during the electrolysis Eq. 5 allows for the continuous addition and dissolution of iron oxide in Eq. 2. Hence, iron is formed by the continuous addition of $\mathrm{Fe}_{2} \mathrm{O}_{3}$ (the principle constituent of iron ore) without the need to add additional lithium oxide. This iron oxide splitting electrolysis mechanism has been delineated in references 5-8, and the minimum electrolysis potential for a related process (for splitting carbon dioxide by electrolysis in molten carbonate) has also been investigated [9]. Instead of the carbothermal production of iron, Eq. 1, the net process for the electrolytic formation of iron metal via the sum of Eqs. 2 and 5 is given by [6]

$\mathrm{Fe}_{2} \mathrm{O}_{3} \rightarrow 2 \mathrm{Fe}+3 / 2 \mathrm{O}_{2}$

In the absence of dissolved iron oxide, rather than

Dissolution : $\mathrm{Fe}_{2} \mathrm{O}_{3}+\mathrm{Li}_{2} \mathrm{O}($ soluble $)$ $\rightarrow 2 \mathrm{LiFeO}_{2}$ (soluble in molten $\mathrm{Li}_{2} \mathrm{CO}_{3}$ )

Electrolysis : $2 \mathrm{LiFeO}_{2}$ (soluble $) \rightarrow 2 \mathrm{Fe}$

$$
+\mathrm{Li}_{2} \mathrm{O}(\text { soluble })+3 / 2 \mathrm{O}_{2}
$$

Net $: \mathrm{Fe}_{2} \mathrm{O}_{3} \rightarrow 2 \mathrm{Fe}+3 / 2 \mathrm{O}_{2}$

Dissolution of carbon dioxide and splitting of the electrolyte lead to carbon formation at $T<900{ }^{\circ} \mathrm{C}$ :

Dissolution : $\mathrm{CO}_{2}+\mathrm{Li}_{2} \mathrm{O}$ (soluble $) \rightarrow \mathrm{Li}_{2} \mathrm{CO}_{3}$

Electrolysis : $\mathrm{Li}_{2} \mathrm{CO}_{3} \rightarrow \mathrm{C}+\mathrm{Li}_{2} \mathrm{O}$ (soluble) $+\mathrm{O}_{2}$

Net : $\mathrm{CO}_{2} \rightarrow \mathrm{C}+1 \mathrm{O}_{2}$

and with the increasing temperature shifts to a carbon monoxide product at $T>900{ }^{\circ} \mathrm{C}$ :

Dissolution : $\mathrm{CO}_{2}+\mathrm{Li}_{2} \mathrm{O}($ soluble $) \rightarrow \mathrm{Li}_{2} \mathrm{CO}_{3}$

Electrolysis : $\mathrm{Li}_{2} \mathrm{CO}_{3} \rightarrow \mathrm{CO}+\mathrm{Li}_{2} \mathrm{O}$ (soluble) $+\mathrm{O}_{2}$

Net : $\mathrm{CO}_{2} \rightarrow \mathrm{CO}+1 / 2 \mathrm{O}_{2}$

The individual anode and cathode reactions can be complex [7-9], but in all cases, $\mathrm{O}_{2}$ is generated at the anode and the reduced carbon or iron product at the cathode. 
Figure 1 presents the observed variation of the iron oxide splitting electrolysis potential at $730{ }^{\circ} \mathrm{C}$ with the increasing current during electrolysis in a $\mathrm{Li}_{2} \mathrm{CO}_{3}$ electrolyte containing $3 \mathrm{mLi}_{2} \mathrm{O}$ and $1.5 \mathrm{~m} \mathrm{Fe}_{2} \mathrm{O}_{3}(\mathrm{~m}=$ molal, moles per $\mathrm{kg} \mathrm{Li}_{2} \mathrm{CO}_{3}$ ). In each case, the electrolysis was conducted for $1 \mathrm{Ah}$ at a $10 \mathrm{~cm}^{2}$ nickel anode and a $10 \mathrm{~cm}$ iron cathode $(10 \mathrm{~h}$ for the $0.1 \mathrm{~A}$ electrolysis, decreasing to $0.2 \mathrm{~h}$ for the $5 \mathrm{~A}$ electrolysis). The expected increase of potential with current density is evident. Not shown is that the electrolysis potential is smaller than the low value of $1.2 \mathrm{~V}$ in the figure for the $0.1 \mathrm{~A}$ electrolysis, and is less than $1 \mathrm{~V}$ when the electrolysis is conducted either at higher temperature, or with a larger anode to diminish the substantial anode $\mathrm{O}_{2}$ evolution polarization contribution to the overpotential [8].

Cross-sectional analysis of the iron in cathode deposit shows that the top layer (nearest the anode) is dominated by $\mathrm{Fe}(\mathrm{III})$, the middle layer by $\mathrm{Fe}(\mathrm{II}, \mathrm{III})$, and the bottom layer on the cathode by $\mathrm{Fe}(0)$. The electrolyte resistance impacts the electrolysis potential at higher current density. The electrolysis potential for the 5 A electrolysis in Fig. 1 decreases by up to $0.8 \mathrm{~V}$ when the anode/cathode spacing is diminished (not shown), but is not observably smaller for the $0.1 \mathrm{~A}$ electrolysis. However, when the inter electrode spacing is closer than that shown in the photo, there is a tendency that an electrical short occurs as the iron metal
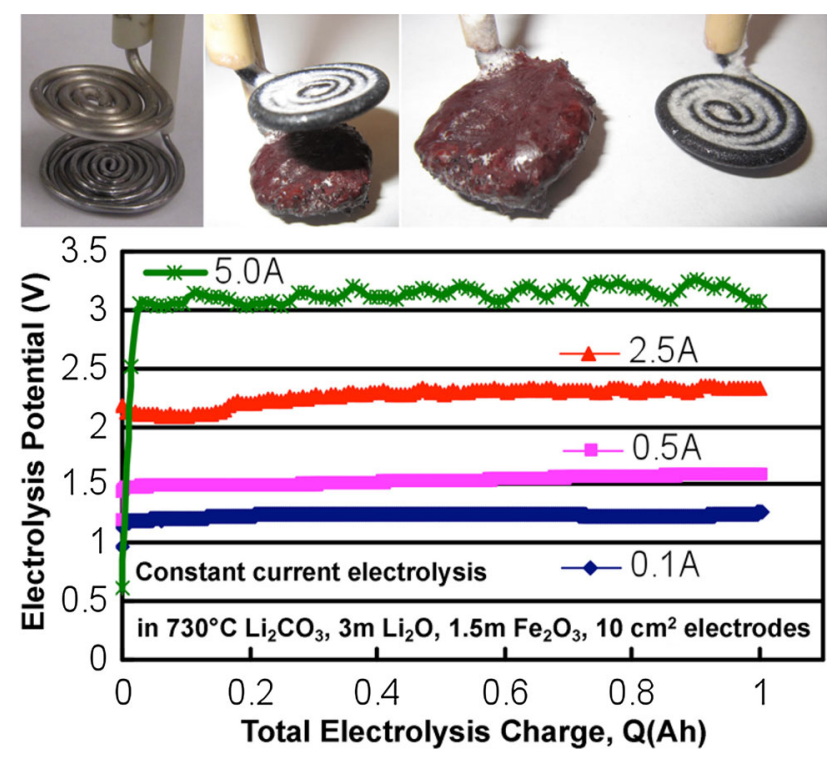

Fig. 1 Variation of the iron oxide splitting electrolysis potential with currents for a fixed $(1 \mathrm{Ah})$ total charge. The electrolysis was conducted in $730{ }^{\circ} \mathrm{C} \mathrm{Li}_{2} \mathrm{CO}_{3}$ with $3 \mathrm{~m} \mathrm{Li}_{2} \mathrm{O}$ and $1.5 \mathrm{~m} \mathrm{Fe}_{2} \mathrm{O}_{3}$ for $1 \mathrm{Ah}$ at a $10 \mathrm{~cm}^{2}$ nickel anode and a $10 \mathrm{~cm}^{2}$ iron cathode. Photos: $10 \mathrm{~cm}^{2}$ nickel anode above a $10 \mathrm{~cm}^{2}$ iron cathode before (left photo) immersion in the electrolyte and after the electrolysis (middle and right photos). Post-electrolysis cathode product is removed, washed, and analyzed for iron metal. The iron wire is re-useable as a cathode product grows from the cathode and contacts the anode during extended (high $\mathrm{Q}$, total charge) electrolysis.

An unexpectedly large effect of current density on iron product particle size formed by electrolysis from molten carbonate is seen by comparison of the SEM in Fig. 2. All of the SEM observations are presented at the same magnification. Although each electrolysis is conducted for 1 Amp hour (Ah) of charge, the iron particle size formed varies by an order of magnitude with current density. In each case, the electrolysis is conducted in $730{ }^{\circ} \mathrm{C}$ molten lithium carbonate containing $3 \mathrm{~m} \mathrm{Li}_{2} \mathrm{O}$ and $1.5 \mathrm{~m} \mathrm{Fe}_{2} \mathrm{O}_{3}$ charge through an oxygen generating $10 \mathrm{~cm}^{2}$ nickel anode and an iron forming $10 \mathrm{~cm}^{2}$ iron cathode. As shown in Fig. 1, product iron was formed at four different current densities, (A) $10 \mathrm{~mA} \mathrm{~cm}{ }^{-2}(0.1 \mathrm{~A}$ electrolysis for $10 \mathrm{~h}$, to $\mathrm{cm}^{-2}$ (2.5A for $\left.0.4 \mathrm{~h}\right)$, or (D) $500 \mathrm{~mA} \mathrm{~cm}{ }^{-2}$ (5 A for $0.2 \mathrm{~h}$ ). The figure demonstrates that the size of deposited Fe varies inversely with current at a fixed charge, varying from 100 to $300 \mu \mathrm{m}$ at a low current density of $10 \mathrm{~mA} \mathrm{~cm}^{-2}$, down to $10-30 \mu \mathrm{m}$ at high current density of $500 \mathrm{~mA} \mathrm{~cm}^{-2}$ for these $1 \mathrm{Ah}$ electrolysis. It is speculated that diffusional (mass transport) limitations imposed by higher current density preferentially support repeated nucleation and growth of new iron particles, rather than ongoing growth of existing iron particles.

In addition to the study of the systematic variation of the iron product micromorphology with current density, oxide concentration, electrolysis temperature, electrolysis time, iron concentration, and electrolysis charge were studied as well (Figs. 2, 4, 5, 6, 7, and 8), which can occur with change in conditions, in this case a change of electrolyte. $\mathrm{LiOH}$ was added to introduce a potential source of bound water in the electrolyte to encourage the possibility of an iron oxide particle formation with the iron product. The use of a mixed cation electrolyte lowers the melting point to encourage some (bound) water retention in the electrolyte. Figure 3 presents SEM of the substantial morphology variation of the iron product that can form during electrolysis under these significantly different electrolysis conditions in molten carbonate. This product was formed at longer electrolysis time $(2 \mathrm{~h}$ compared to $0.4 \mathrm{~h}$ at $2.5 \mathrm{~A}$ previously), lower temperature $\left(650{ }^{\circ} \mathrm{C}\right.$ compared to $730{ }^{\circ} \mathrm{C}$ ), and in a different electrolyte of $\mathrm{Li}_{1.34} \mathrm{Ba}_{0.08}$ $\mathrm{Ca}_{0.1} \mathrm{CO}_{3}$ with $6 \mathrm{~m} \mathrm{LiOH}$ and $1.5 \mathrm{~m} \mathrm{Fe}_{2} \mathrm{O}_{3}$.

The product particle size formed during a $250 \mathrm{~mA} \mathrm{~cm}^{-2}$ electrolysis shown in Fig. 3 is similar in size to that formed in the $\mathrm{Li}_{2} \mathrm{CO}_{3}$ electrolyte in Fig. 2 at $2.5 \mathrm{~A}$ the same current density, but the product appears more granular. In Fig. 3, this single iron product is shown at magnifications increasing from $\times 270$ (top left) to $\times 14500$ in bottom right. Unlike the previous higher-temperature electrolyte, which contained $\mathrm{Li}_{2} \mathrm{O}$, this electrolyte contains $\mathrm{LiOH}$, which 
Fig. 2 SEM of the iron metal product formed at different electrolysis current densities in identical electrolytes and with the same electrolysis charge (1 Ah). The electrolyte is $730{ }^{\circ} \mathrm{C} \mathrm{Li}_{2} \mathrm{CO}_{3}$ with $3 \mathrm{~m} \mathrm{Li}_{2} \mathrm{O}$ and $1.5 \mathrm{~m} \mathrm{Fe}_{2} \mathrm{O}_{3}$. Iron is formed by electrolytic splitting of iron oxide in carbonate at the indicated currents of $0.1,0.5$, 2.5 , or $5 \mathrm{~A}$. The electrolysis was conducted at a $10 \mathrm{~cm}^{2}$ nickel anode and a $10 \mathrm{~cm}^{2}$ iron cathode. Post-electrolysis cathode product is removed and washed

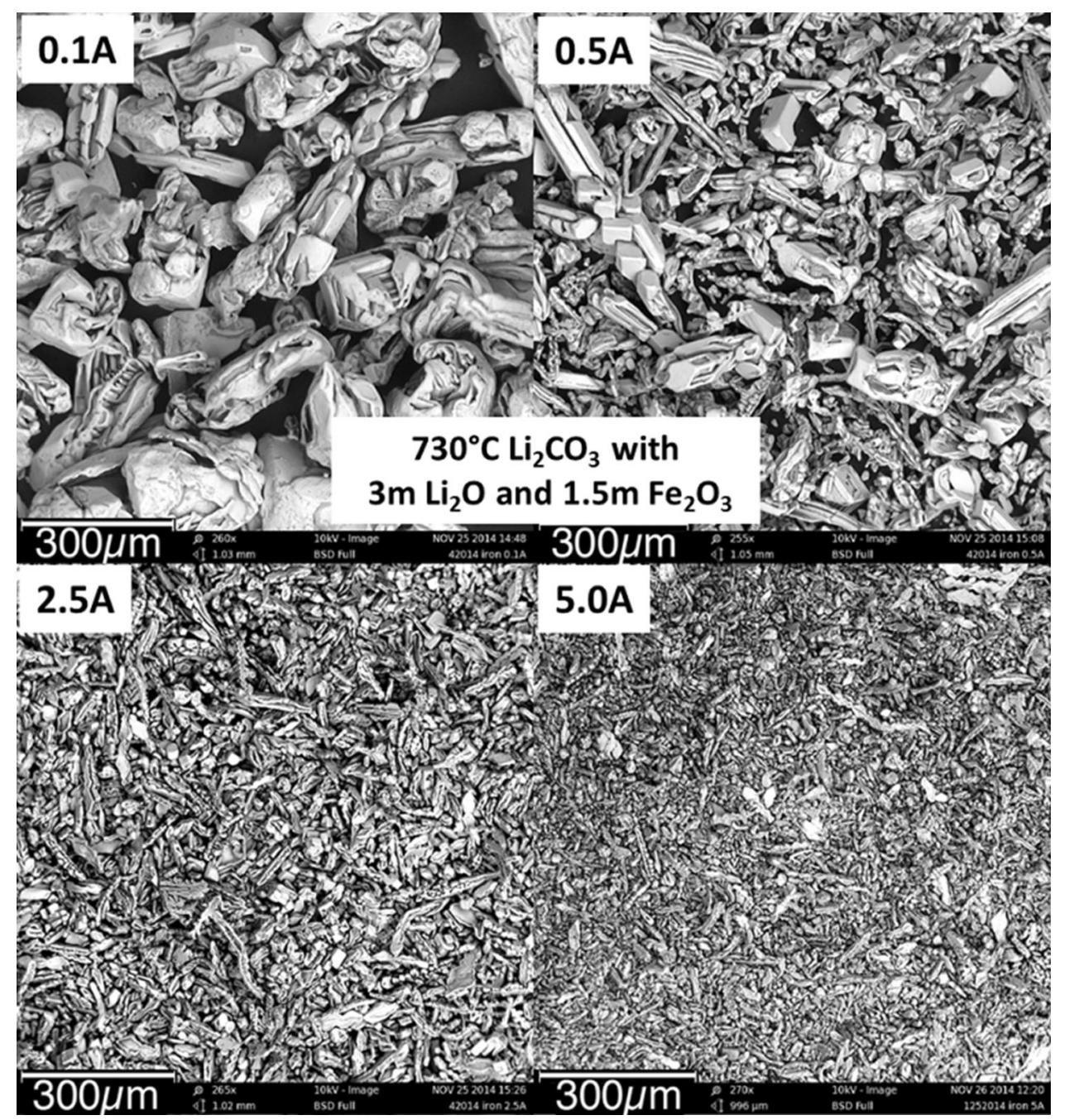

allows water to be available in accordance with the equilibrium:

$2 \mathrm{LiOH} \rightleftharpoons \mathrm{Li}_{2} \mathrm{O}+\mathrm{H}_{2} \mathrm{O}$

It is seen in Fig. 3 that the iron product is strongly affected by the electrolyte deposition conditions. In particular, the available water induces an overlayer of $\mathrm{Fe}_{3} \mathrm{O}_{4}$ (as determined by EDS analysis of the sample, and the known octahedral crystal shape of magnetite).

Figure 4 presents the effect of $\mathrm{Li}_{2} \mathrm{O}$ concentration in a $730{ }^{\circ} \mathrm{C}$ molten $\mathrm{Li}_{2} \mathrm{CO}_{3}$ electrolyte containing $1.5 \mathrm{~m} \mathrm{Fe}_{2} \mathrm{O}_{3}$, on the morphology of the cathode electrolysis product; specifically with either $1.5 \mathrm{~m} \mathrm{Li}_{2} \mathrm{O}$ (left side of the figure), $3 \mathrm{~m} \mathrm{Li}_{2} \mathrm{O}$ (middle) or $9 \mathrm{~m} \mathrm{Li}_{2} \mathrm{O}$ (right). The 1 Ah electrolysis are conducted at either low ( $0.1 \mathrm{~A}-$ top row of the figure) or high 5 A (bottom row) constant current. In accordance with Eq. 2, the electrolytes are composed of dissolved $3 \mathrm{~m}$ $\mathrm{LiFeO}_{2}$ either without surplus $\mathrm{Li}_{2} \mathrm{O}$ (left side), or with $1.5 \mathrm{~m}$ (middle) or $7.5 \mathrm{~m}$ (right) surplus $\mathrm{Li}_{2} \mathrm{O}$. At $0.1 \mathrm{~A}$, the low oxide electrolyte generates 3 -fold longer ( $\sim 600 \mu \mathrm{m}$ length) iron particles (top, left). For the $5 \mathrm{~A}$ electrolysis, the production of longer iron particles is also evident from the low oxide electrolyte (bottom, left). $\mathrm{Li}_{2} \mathrm{O}$ concentrations have also been observed to effect the morphology of carbon nanotubes and nanofibers grown from molten $\mathrm{Li}_{2} \mathrm{CO}_{3}$ (in the absence of added iron oxide), and specifically that higher $\mathrm{Li}_{2} \mathrm{O}$ concentrations lead to the growth of tangled, rather than straight nanostructures [27, 28].

Variation of lithium oxide concentration in the molten carbonate electrolyte has several effects on the iron oxide electrolysis in addition to the product morphology as observed in Fig. 4. Consistent with prior observations, the electrolysis potential decreases with the increasing $\mathrm{Li}_{2} \mathrm{O}$ concentration [8]. For example, in the $5 \mathrm{~A}$ constant current electrolysis at $730{ }^{\circ} \mathrm{C}$ in the $3 \mathrm{~m} \mathrm{Li}_{2} \mathrm{O}$, the average potential is $3.1 \mathrm{~V}$, but we observe that a higher $3.4 \mathrm{~V}$ during the $1.5 \mathrm{~m} \mathrm{Li}_{2} \mathrm{O}$ electrolysis, and a lower $2.9 \mathrm{~V}$ average electrolysis in the $9 \mathrm{~m} \mathrm{Li}_{2} \mathrm{O}$ electrolyte. 
Fig. 3 Variation of the iron product shape with a substantial change in electrolysis conditions. The $1.5 \mathrm{~m} \mathrm{Fe}_{2} \mathrm{O}_{3}$ electrolysis is conducted in $650{ }^{\circ} \mathrm{C} \mathrm{Li}_{1.34} \mathrm{Ba}_{0.08} \mathrm{Ca}_{0.1} \mathrm{CO}_{3}$ with $6 \mathrm{~m} \mathrm{LiOH}$ compared to $730{ }^{\circ} \mathrm{C} \mathrm{Li}_{2} \mathrm{CO}_{3}$ with $3 \mathrm{~m} \mathrm{Li}_{2} \mathrm{O}$ in Fig. 2. Electrodes are as described in the Fig. 2 caption, and the current is the same as in the 2.5 A Fig. 2, but is applied for $2 \mathrm{~h}(5 \mathrm{Ah})$. Both the deposited iron and the formation of a product of octahedral magnetite, $\mathrm{Fe}_{3} \mathrm{O}_{4}$ are observed

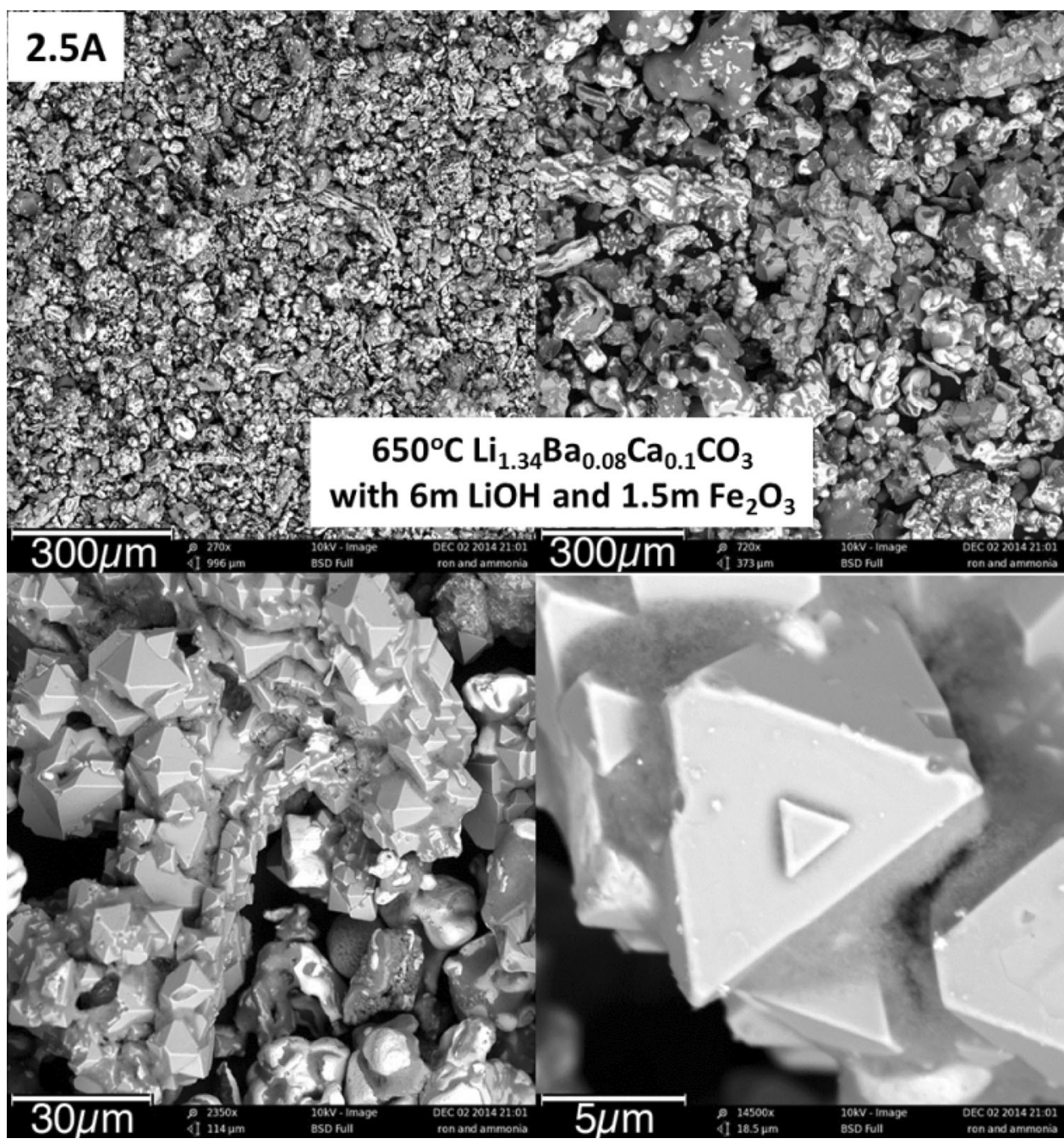

According to Eq. 6, one equivalent of metallic iron can be formed with three equivalents of applied charge. The iron electrolysis columbic efficiency is defined as $100 \% \times$ the measured moles of iron product divided by $3 \times$ the measured equivalents of charge passed during the electrolysis $(1 \mathrm{Ah}=3600$ coulombs $=0.037$ Faraday of electrons). Generally, STEP iron coulombic efficiency approaches $100 \%$ [7]. Any losses from this $100 \%$ coulombic efficiency can be attributed to (i) the partial reduction to $\mathrm{Fe}_{3} \mathrm{O}_{4}$, rather than to iron metal, visible as a mixed black (magnetite) product in the outer perimeter of the cathode product and by chemical analysis [7]; (ii) nickel deposited at the cathode as a consequence of anodic corrosion; (iii) chemical re-oxidation of the iron metal product by high oxide concentrations; or (iv) the co-deposition of reduced carbon in the iron which is only observed to occur at higher potentials than for iron deposition $[6,11]$. We have previously detailed the thin oxide layer that develops on the nickel anode, and that is highly stable toward $\mathrm{O}_{2}$ formation in molten $\mathrm{Li}_{2} \mathrm{CO}_{3}$ containing up to $5 \mathrm{~m} \mathrm{Li}_{2} \mathrm{O}$ [8]. Higher $\mathrm{Li}_{2} \mathrm{O}$ concentrations lead to corrosion of the anode and release of low concentrations of oxidized nickel into the electrolyte. The majority of the applied current yields iron metal during electrolysis in either low or moderate $\mathrm{Li}_{2} \mathrm{O}$-containing electrolytes (left and middle of Fig. 4). However, in the high oxide electrolyte prepared with $9 \mathrm{~m} \mathrm{Li}_{2} \mathrm{O}$, corrosion of the anode is visible, and the iron formed is measured at $6 \%$ columbic efficiency.

Elevated temperature can decrease the electrolysis potential and power required for iron deposition. At $950{ }^{\circ} \mathrm{C}$, rather than $730{ }^{\circ} \mathrm{C}$, the average electrolysis potential drops from $3.1 \mathrm{~V}$ to $1.9 \mathrm{~V}$ at $5 \mathrm{~A}$ in the $3 \mathrm{~m} \mathrm{Li}_{2} \mathrm{O}$, $1.5 \mathrm{~m} \mathrm{Fe}_{2} \mathrm{O}_{3}$ lithium carbonate electrolyte, and drops from $1.2 \mathrm{~V}$ down to 0.6 to $0.8 \mathrm{~V}$ at $0.1 \mathrm{~A}$. Interestingly as seen in Fig. 5, at $950{ }^{\circ} \mathrm{C}$ the product particle size from the $5 \mathrm{~A}$ electrolysis is larger than that observed for the $730{ }^{\circ} \mathrm{C}$ electrolysis product seen in Fig. 2. 


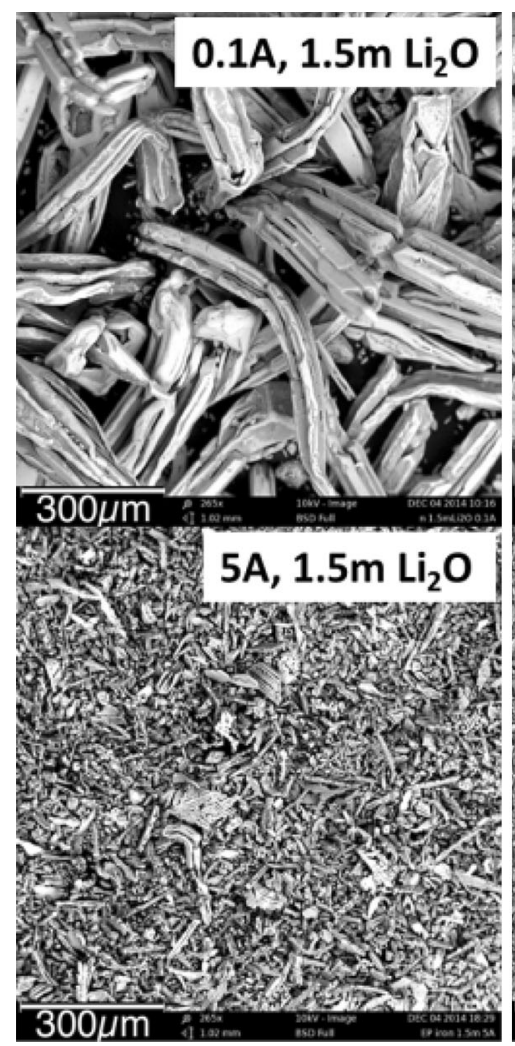

Fig. 4 SEM of the cathode product formed in molten lithium carbonate with various, increasing concentrations of $\mathrm{Li}_{2} \mathrm{O}$. The electrolyte is $730{ }^{\circ} \mathrm{C} \mathrm{Li}_{2} \mathrm{CO}_{3}$ with $1.5 \mathrm{~m} \mathrm{Fe}_{2} \mathrm{O}_{3}$ and with the indicated $1.5,3$, or $9 \mathrm{~m}$ concentration of $\mathrm{Li}_{2} \mathrm{O}$. Iron is formed by a $1 \mathrm{Ah}$

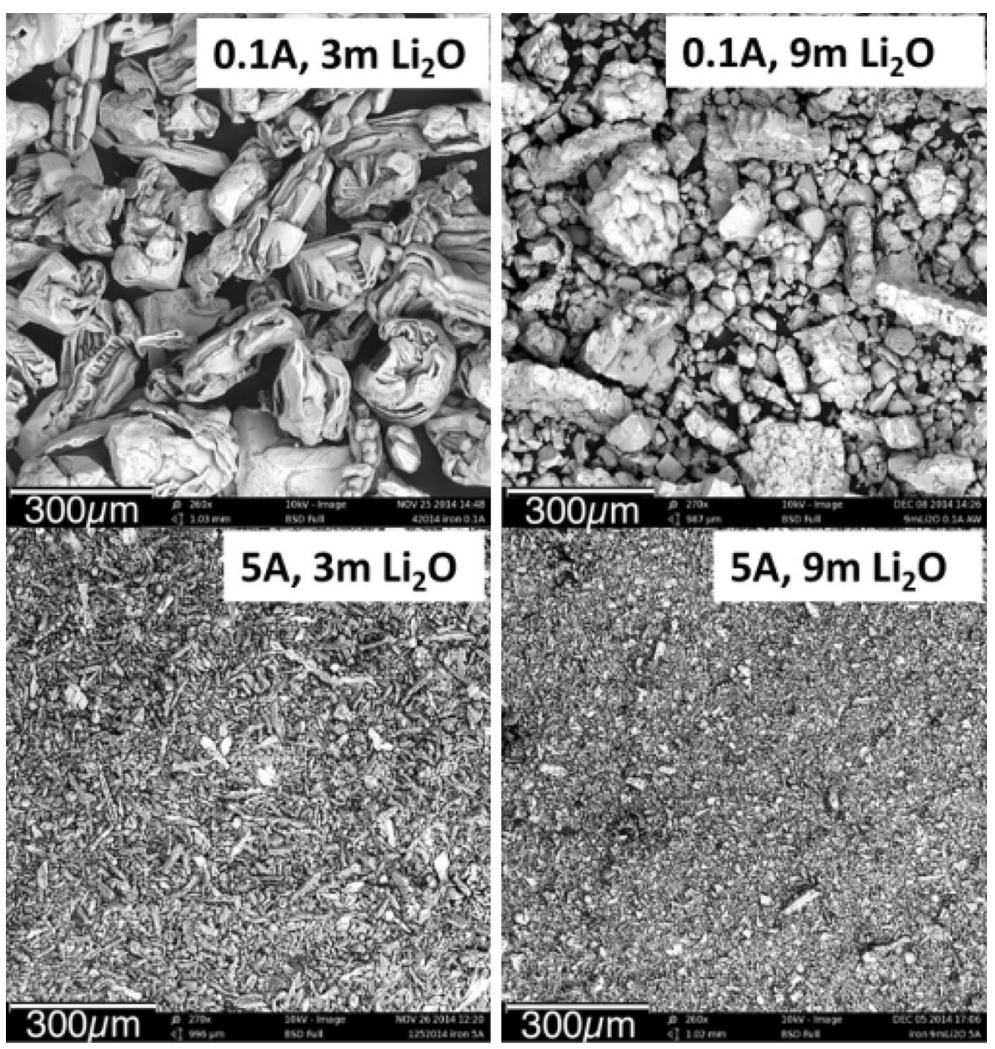

electrolysis between a $10 \mathrm{~cm}^{2} \mathrm{Ni}$ anode and a $10 \mathrm{~cm}^{2}$ iron cathode at the indicated current (either 0.1 or $5 \mathrm{~A}$ ). Expanded copies of the middle SEM are seen in Figs. 2a, d
Fig. 5 SEM of the product formed by elevated temperature, 1 Ah electrolysis at $950{ }^{\circ} \mathrm{C}$ in $\mathrm{Li}_{2} \mathrm{CO}_{3}$ with $3 \mathrm{~m} \mathrm{Li}_{2} \mathrm{O}$ and $1.5 \mathrm{~m} \mathrm{Fe}_{2} \mathrm{O}_{3}$. Electrolysis is driven at the indicated $0.1 \mathrm{~A}$ or 5 A current. Electrodes are as described in the Fig. 2 caption

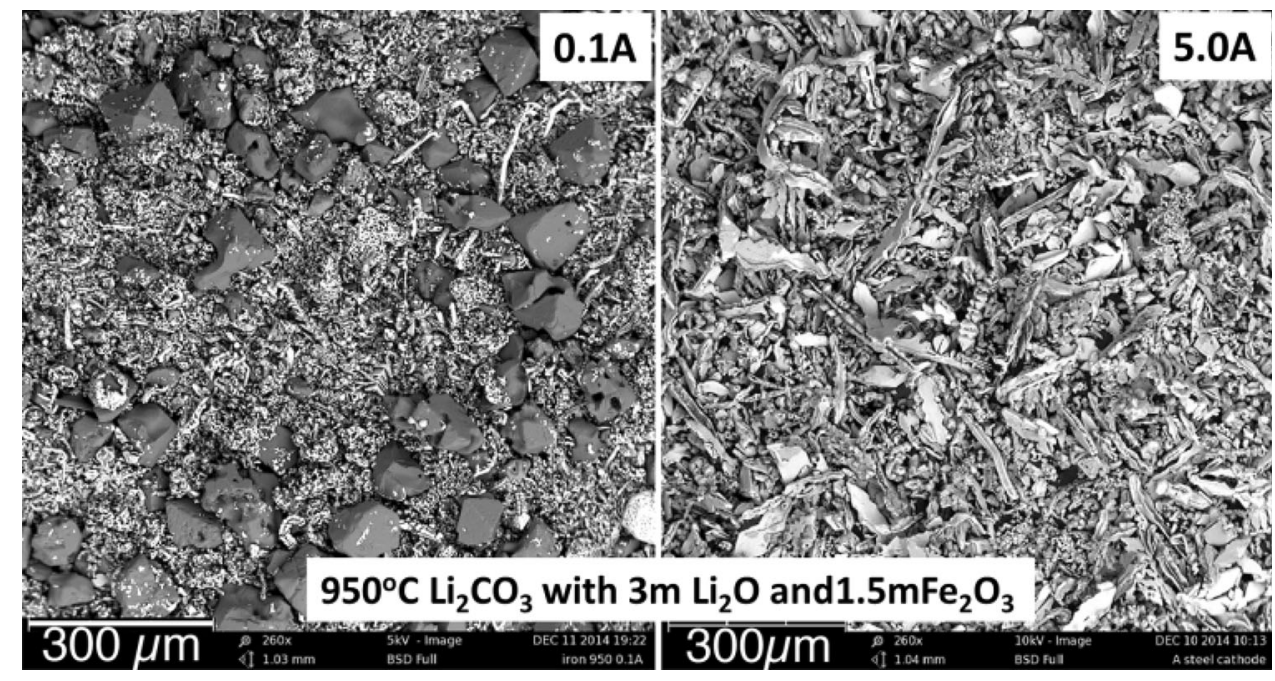

Assuming constant coulombic efficiency and density at constant current, toward a linear increase in volume, the diameter of the iron product particles would be expected to increase linearly with the cube root of the relative increase in deposition time. As compared in Figs. 2 and 6, by shortening the electrolysis time at constant current, the iron 
Fig. 6 SEM of Fe variation with electrolysis time. Electrolysis conducted at $0.1 \mathrm{~A}$ (top) as indicated for either $2 \mathrm{~h}$ (total charge $0.2 \mathrm{Ah}$ ) or $10 \mathrm{~h}$ (total charge $1 \mathrm{Ah}$ ), or at $5 \mathrm{~A}$ (bottom) as indicated for $0.2 \mathrm{~h}$ (total charge $1 \mathrm{Ah}$ ) or $0.5 \mathrm{~h}$ (total charge $2.5 \mathrm{Ah}$ )

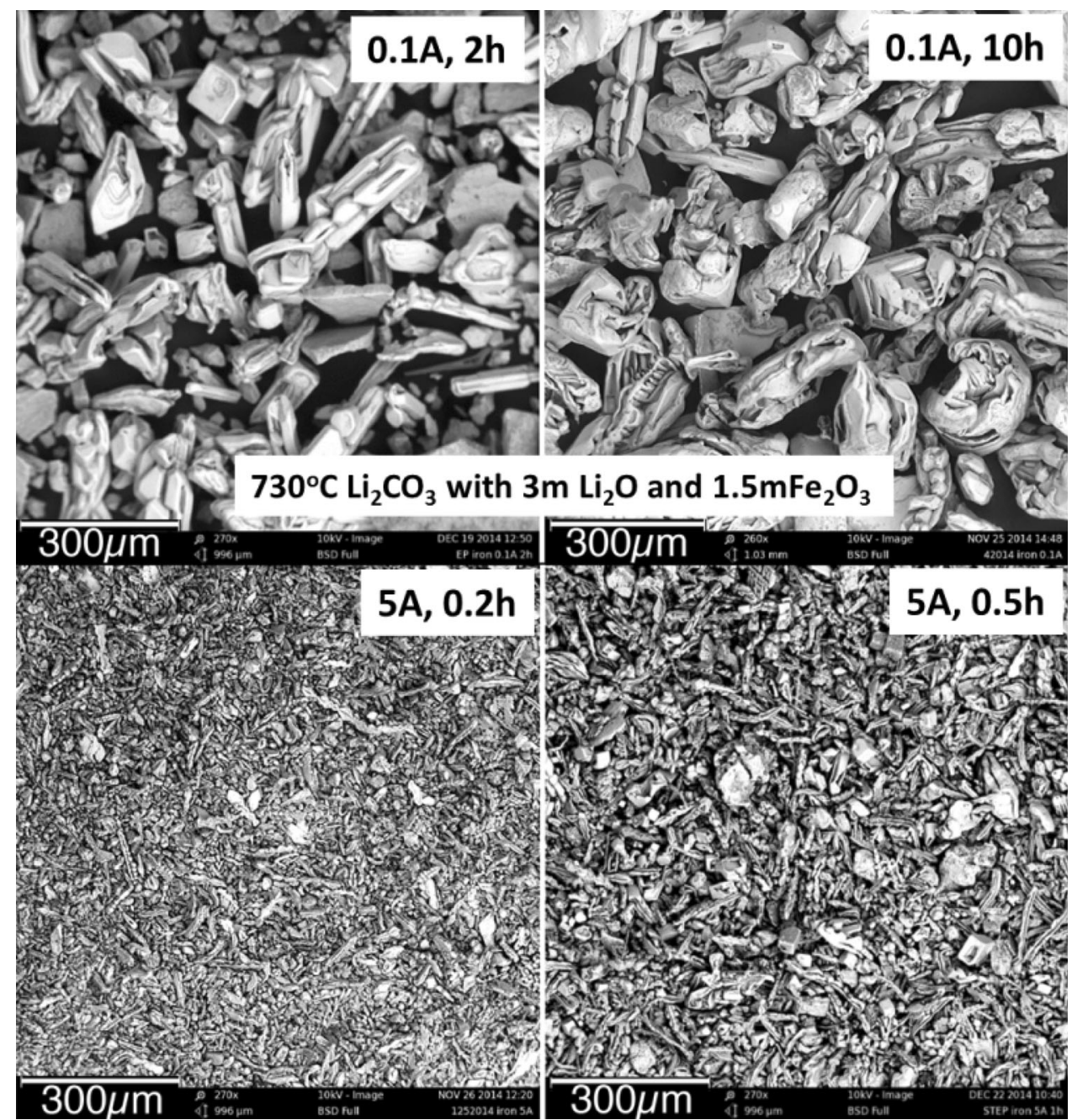

product particle size is smaller, and in turn it becomes larger by prolonging the electrolysis time in the $730{ }^{\circ} \mathrm{C}$ $\mathrm{Li}_{2} \mathrm{CO}_{3}$ with $3 \mathrm{~m} \mathrm{Li}_{2} \mathrm{O}$ and $1.5 \mathrm{~m} \mathrm{Fe}_{2} \mathrm{O}_{3}$ electrolyte.

No significant effect on iron product particle size was observed when the iron oxide was electrolyzed in molten lithium carbonate under $\mathrm{CO}_{2}$ gas, rather than under nitrogen gas. Similarly, the use of an oversized anode did not significantly alter the iron particle size. Specifically, the alumina crucible was replaced by a nickel crucible, and the $10 \mathrm{~cm}^{2}$ wound nickel wire anode was replaced by the inner walls of the nickel crucible. The cathode product from this electrolysis conducted in $730{ }^{\circ} \mathrm{C} \mathrm{Li}_{2} \mathrm{CO}_{3}, 3 \mathrm{mLi}_{2} \mathrm{O}, 1.5 \mathrm{~m}$ $\mathrm{Fe}_{2} \mathrm{O}_{3}$ at $0.1 \mathrm{~A}$ for $10 \mathrm{~h}$ was similar to the product shown in Fig. 2a, although the electrolysis occurred at a lower average potential of $0.98 \mathrm{~V}$ due to the larger anode surface area.

Figure 7 compares the iron variation with $\mathrm{LiFeO}_{2}$ concentration in the $730{ }^{\circ} \mathrm{C}$ lithium carbonate electrolytes. In each case, in accordance with Eq. 2, the $\mathrm{LiFeO}_{2}$ concentration is prepared by dissolution of equal concentrations of $1 / 2 \mathrm{Fe}_{2} \mathrm{O}_{3}+1 / 2 \mathrm{Li}_{2} \mathrm{O}$. Previously in molten $\mathrm{Li}_{2}$ $\mathrm{CO}_{3}$, cyclic voltammetry has observed a single peak related to the reduction of $\mathrm{Fe}$ (III) for dissolved $\mathrm{Fe}_{2} \mathrm{O}_{3}$, and two peaks related the reduction of $\mathrm{Fe}(\mathrm{II})$ and $\mathrm{Fe}$ (III) for dissolved $\mathrm{Fe}_{3} \mathrm{O}_{4}$ [5]. The concentrations of $\mathrm{Fe}(\mathrm{III})$, dissolved as $\mathrm{LiFeO}_{2}$, significantly impact the electrolysis product in molten carbonates. In the absence of $\mathrm{Fe}(\mathrm{III})$ added to the electrolyte, the cathode product from molten lithium carbonate is either pure solid carbon (at temperatures at or below $750{ }^{\circ} \mathrm{C}$ ) or a mix of carbon and carbon monoxide gas at temperatures up to $900{ }^{\circ} \mathrm{C}$, or carbon monoxide at temperature of $950{ }^{\circ} \mathrm{C}$ instead of an iron metal cathode product. At low concentration of $\mathrm{Fe}(\mathrm{III})$, such as $0.2 \mathrm{~m}$ $\mathrm{LiFeO}_{2}$ (formed by the dissolution of $0.1 \mathrm{~m} \mathrm{Li}_{2} \mathrm{O}$ and $0.1 \mathrm{~m} \mathrm{Fe}_{2} \mathrm{O}_{3}$ in $\mathrm{Li}_{2} \mathrm{CO}_{3}$ at $730{ }^{\circ} \mathrm{C}$ ), the cathode product is a mix of iron and solid carbon. This occurs even at a low current density of $10 \mathrm{~mA} \mathrm{~cm}{ }^{-2}$, and the product particle size is small as seen in the left and middle top portions of 


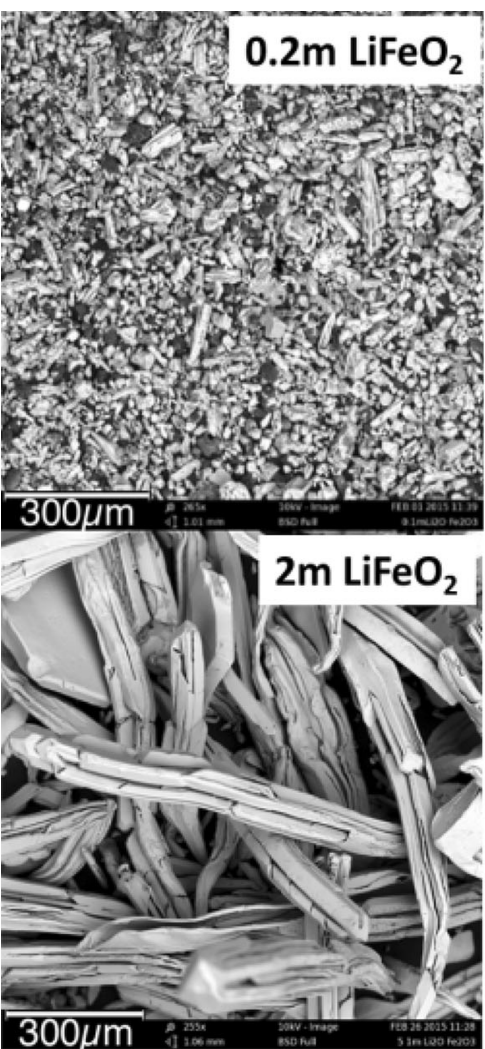

Fig. $7 \mathrm{Fe}$ variation with $\mathrm{LiFeO}_{2}$ concentrations $\left(\mathrm{Li}_{2} \mathrm{CO}_{3}\right.$ electrolytes with equimolal $\mathrm{Li}_{2} \mathrm{O}$ and $\left.\mathrm{Fe}_{2} \mathrm{O}_{3}\right)$. Iron formed at $0.1 \mathrm{~A}$ for $10 \mathrm{~h}(1 \mathrm{Ah}$ of charge). In the top left and middle panels, the electrolysis was conducted with $0.2 \mathrm{~m} \mathrm{LiFeO}_{2}$ (SEM shown, respectively, at $\times 265$ or $\times 580$ magnification $)$. In the top right panel with $1 \mathrm{~m} \mathrm{LiFeO}_{2}(\times 265$
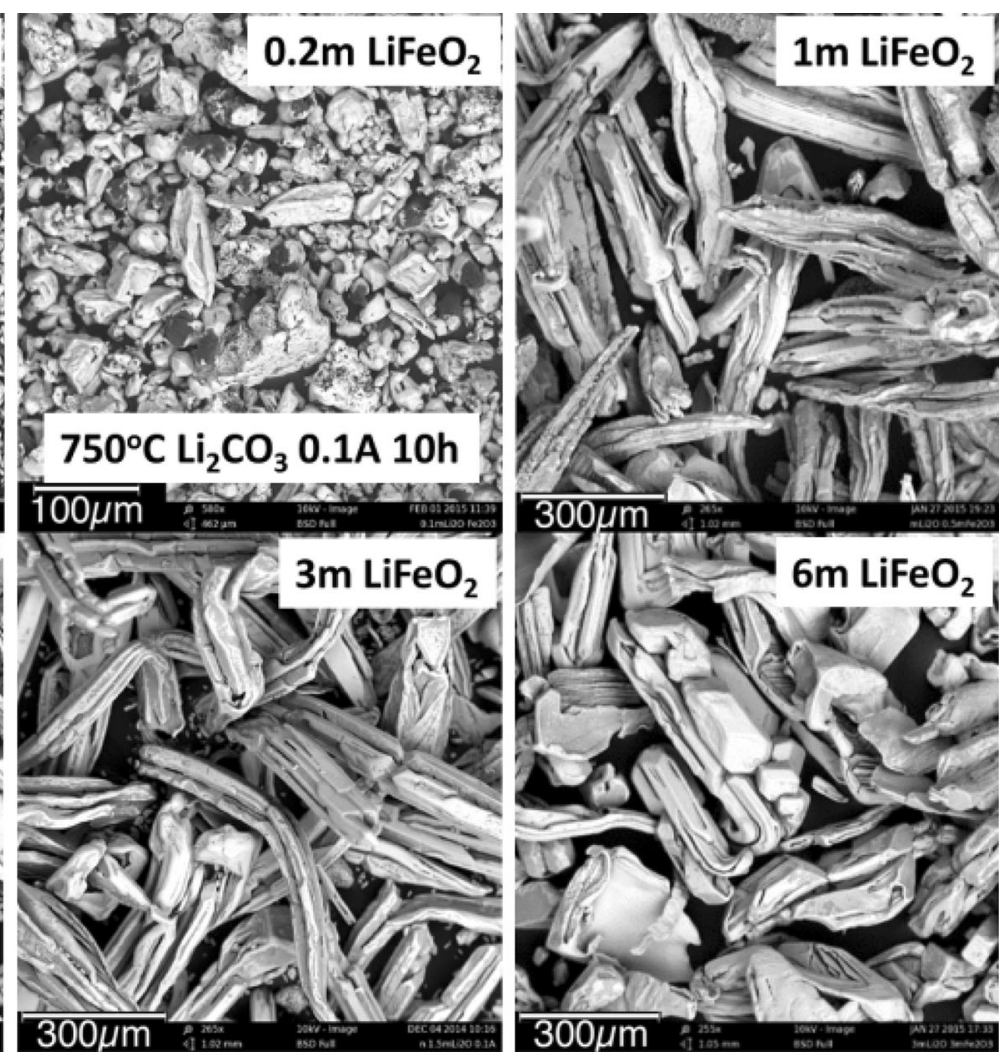

Fig. 7. EDS of the black portions shows they are carbon, and the remainder iron. Hence, low Fe(III) concentrations provide a path to smaller STEP iron particles (albeit mixed with carbon). As seen in the other panels of Fig. 7, higher concentrations of $\mathrm{LiFeO}_{2}$ (comparing 1,2,3 and $6 \mathrm{~m}$ concentrations) generate large iron metallic products. The iron electrolysis product particles are marginally larger at the highest $(6 \mathrm{~m}) \mathrm{LiFeO}_{2}$ concentration (figure bottom right).

The cathode product is easily removed from wound steel wire cathode as it drops off upon uncoiling the wire. The fraction of trapped electrolyte retained in the cooled deposited STEP metal iron product is high. This electrolyte can be removed by washing and drying. The iron product is typically formed at high coulombic efficiency, and the iron metal formed is pure (not oxidized). However, the deposited iron resides with a large amount of electrolyte that is also extracted with the cathode. The percent by mass of iron metal in the product is $5-8 \%$, and the remainder is comprised of electrolyte. Extended charge electrolyses increase the percent by mass of iron metal in the product and decreases the amount of electrolyte contained with the magnification), and in the bottom panel with either $2 \mathrm{~m}($ left $), 3 \mathrm{~m}$ (middle), or $6 \mathrm{~m}$ (right) $\mathrm{LiFeO}_{2}$. Electrolyses were conducted at $750{ }^{\circ} \mathrm{C}$, rather than $730{ }^{\circ} \mathrm{C}$, to improve dissolution of the concentrated $\mathrm{Fe}(\mathrm{III})$ electrolytes

product. Compared to the 1 Ah electrolysis in Fig. 2 (or the 0.2 or 2.5 Ah electrolysis in Fig. 6), Fig. 8 presents SEM of the iron product subsequent to a single 25 Ah electrolysis $\left(1 \mathrm{~A}\right.$ current $\left(100 \mathrm{~mA} / \mathrm{cm}^{2}\right)$ for $\left.25 \mathrm{~h}\right)$. The percent of iron by mass in the product has increased to $11.5 \%$, and as seen, the iron particle size increases to $\sim 500 \mu \mathrm{m}$ (ranging from 100 to $700 \mu \mathrm{m}$ particle size).

\section{Conclusions}

Iron metal can be formed from iron oxide without the large carbon dioxide emissions that occur with the conventional industrial iron smelting, when the iron is formed by electrolysis in molten carbonate-containing dissolved $\mathrm{Fe}_{2} \mathrm{O}_{3}$ and $\mathrm{Li}_{2} \mathrm{O}$. In this study, we show that iron product micromorphology is substantially affected by the electrolysis conditions through the systematic variation of the electrolysis time, current density, temperature, and iron reactant and oxide concentrations. The iron product size decreases in size by a factor of 30 when the electrolysis current density is increased from 10 to $500 \mathrm{~mA} \mathrm{~cm}^{-2}$. 
Fig. 8 Fe size subsequent to extended duration and charge electrolysis in $\mathrm{Li}_{2} \mathrm{CO}_{3}$ electrolytes. Variation of $\mathrm{Fe}$ iron formed in a single electrolysis at $1 \mathrm{~A}$ for $25 \mathrm{~h}$ (25 Ah of charge) at a $10 \mathrm{~cm}^{2}$ iron cathode in $750{ }^{\circ} \mathrm{C} \mathrm{Li}_{2} \mathrm{CO}_{3}$ containing $6 \mathrm{~m} \mathrm{LiFeO}_{2}(3 \mathrm{~m}$ $\mathrm{Li}_{2} \mathrm{O}$ and $3 \mathrm{~m} \mathrm{Fe}_{2} \mathrm{O}_{3}$ )

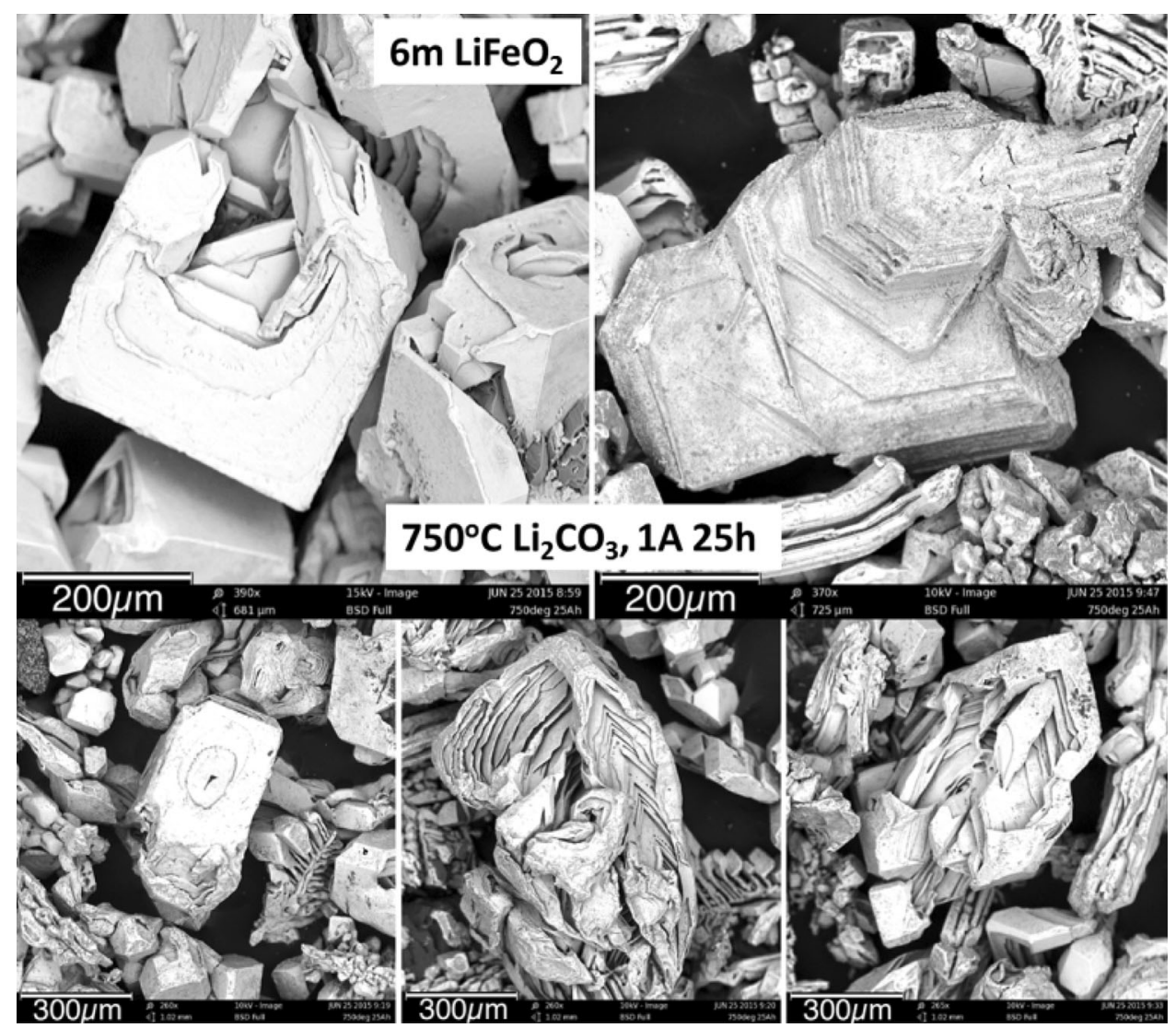

Large $(\sim 500 \mu \mathrm{m}) \mathrm{Fe}$ is formed at low current densities during extended electrolysis, or at high $\mathrm{Fe}(\mathrm{III})$ concentrations. Small $(\sim 10 \mu \mathrm{m}) \mathrm{Fe}$ is formed at high current density and low concentration of $\mathrm{Fe}(\mathrm{III})$. The smallest particles generated are worthy of further study as catalysts, and were produced under conditions of the highest current and shortest electrolysis time. The iron product contains an observed magnetite overlayer when formed with hydroxide $(\mathrm{LiOH})$ rather than oxide $\left(\mathrm{Li}_{2} \mathrm{O}\right)$ added to the electrolyte. The observed deposited iron product particles are fiber shaped from equal molals of $\mathrm{Li}_{2} \mathrm{O}$ and $\mathrm{Fe}_{2} \mathrm{O}_{3}$, but particlelike from electrolytes with surplus $\mathrm{Li}_{2} \mathrm{O}$. Iron is formed at high current efficiency, and the observed electrolysis potential decreases with (i) the decreasing current density, (ii) the addition of $\mathrm{Li}_{2} \mathrm{O}$, (iii) the increasing anode area, and (iv) the increasing temperature.

Acknowledgments This project was supported in part by a grant from the United States National Science Foundation 1230732.

Open Access This article is distributed under the terms of the Creative Commons Attribution 4.0 International License (http://crea tivecommons.org/licenses/by/4.0/), which permits unrestricted use, distribution, and reproduction in any medium, provided you give appropriate credit to the original author(s) and the source, provide a link to the Creative Commons license, and indicate if changes were made.

\section{References}

1. Bloom B (2010) Iron, steel and cement production. The encyclopedia of earth. http://www.eoearth.org/view/article/161510/. Accessed 16 Dec 2010

2. Wang D, Gmitter AJ, Sadoway DR (2011) Production of oxygen gas and liquid metal by electrochemical decomposition of molten iron oxide. J Electrochem Soc 158:E51-E54

3. Kim H, Paramore J, Allanore A, Sadoway DR (2011) Electrolysis of molten iron oxide with an iridium anode: the role of electrolyte basicity. J Electrochem Soc 158:E101-E105

4. Allanore A, Yin L, Sadoway DR (2013) A new anode material for oxygen evolution in molten oxide electrolysis. Nature 497:353-356

5. Licht S, Wang B (2010) High solubility pathway for the carbon dioxide free production of iron. Chem Comm 47:7004-7006

6. Licht S, Wu H, Zhang Z, Ayub H (2011) Chemical mechanism of the high solubility pathway for the carbon dioxide free production of iron. Chem Comm 46:3081-3083

7. Cui B, Licht S (2013) Critical STEP advances for sustainable iron production. Green Chem 15:881-884

8. Licht $\mathrm{S}, \mathrm{Wu} \mathrm{H}$ (2011) STEP Iron, a Chemistry of iron formation without $\mathrm{CO}_{2}$ emission: molten carbonate solubility and electrochemistry of iron ore impurities. J Phys Chem C 115:25138-25157

9. Ren J, Lau J, Lefler MJ, Licht S (2015) The minimum electrolytic energy needed to convert carbon dioxide to carbon by electrolysis in carbonate melts. J Phys Chem C 119:22342-22349

10. Licht S (2009) STEP (Solar Thermal Electrochemical Photo) generation of energetic molecules: a solar chemical process to 
end anthropogenic global warming. J Phys Chem C 113:16283-16292

11. Licht S, Cui B, Wang B, Li F-F, Lau J, Liu S (2014) Ammonia synthesis by $\mathrm{N}_{2}$ and steam electrolysis in molten hydroxide suspensions of nanoscale $\mathrm{Fe}_{2} \mathrm{O}_{3}$. Science 345:637-640

12. Licht S (2003) Solar water splitting to generate hydrogen fuel: photothermal electrochemical analysis. J Phys Chem B 107:4253-4260

13. Licht S, Halperin L, Kalina M, Zidman M, Halperin N (2003) Electrochemical potential tuned water splitting. Chem Comm 24:3006-3007

14. Licht S, Wang B, Ghosh S, Ayub H, Jiang D, Ganley J (2010) A new solar carbon capture process: solar thermal electrochemical photo (STEP) carbon capture. J Phys Chem Lett 1:2363-2368

15. Licht S (2011) Efficient solar-driven synthesis, carbon capture, and desalinization, STEP: solar thermal electrochemical production of fuels, metals, bleach. Adv Mater 47:5592-5612

16. Licht S, Wu H, Hettige C, Wang B, Asercion J, Lau J, Stuart J (2012) STEP cement: solar thermal electrochemical production of $\mathrm{CaO}$ without $\mathrm{CO}_{2}$ emission. Chem Comm 48:6019-6021

17. Zhu Y, Wang H, Wang B, Liu X, Wu H, Licht S (2016) One-pot synthesis of carbon nanofibers from $\mathrm{CO}_{2}$. Appl Cat $\mathrm{B}$ 193:151-159

18. Li F-F, Lau J, Licht S (2015) Sungas instead of syngas: efficient coproduction of $\mathrm{CO}$ and $\mathrm{H}_{2}$ with a single beam of sunlight. Adv Science 1500260:1-5

19. Licht S, Cui B, Wang B (2013) STEP carbon capture: the barium advantage. $\mathrm{J} \mathrm{CO}_{2}$ Util 2:58-63

20. Li F-F, Liu S, Cui B, Lau J, Stuart J, Wang B, Licht S (2015) A one pot synthesis of hydrogen and carbon fuels from water and carbon dioxide. Adv Energy Mater 5:1401791-1-7
21. Gao GF, Li YC, Chen Y (2016) Dynamic response for porous epoxy resin matrix composites filled with iron powder at different strain rates and constitutive relationships. Mech Adv Mat Struct 23:811-868

22. Qing YC, Min DD, Zhou YY, Luo F, Zhou WC (2015) Graphene nanosheet- and flake carbonyl iron particle-filled epoxy-silicone composites as thin-thickness and wide-bandwidth microwave absorber. Carbon 86:98-107

23. Hola K, Markova Z, Zoppellaro G, Tucek J, Zboril R (2015) Tailored functionalization of iron oxide nanoparticles for MRI, drug delivery, magnetic separation and immobilization of biosubstances. Biotech Adv 33:1162-1176

24. Buceta B, Yoland P, Vázquez-Vázque C, Rivas J, López-Quintela M (2014) Metallic clusters: theoretical background, properties and synthesis in microemulsions. Catalysts 4:356-374

25. Gao F, Goodman DW (2012) Simulating the complexities of heterogeneous catalysts. Ann Rev Phys Chem 63:265-286

26. Li F-F, Licht S (2014) Advances in understanding the mechanism and improved stability of the synthesis of ammonia from air and water in hydroxide suspensions of nanoscale $\mathrm{Fe}_{2} \mathrm{O}_{3}$. Inorg Chem 53:10042-10044

27. Ren J, Li FF, Lau J, Gonzalez-Urbina Licht S (2015) One-pot synthesis of carbon nanofibers from $\mathrm{CO}_{2}$. Nano Lett 15:6142-6148

28. Licht S, Douglas A, Ren J, Carter R, Lefler M, Pint CL (2016) Carbon nanotubes produced from ambient carbon dioxide for environmentally sustainable lithium-ion and sodium-ion battery anodes. ACS Cent Sci. doi:10.1021/acscentsci.5b00400 